\title{
Ethical Dilemma and Research Methodology of Social Sciences
}

Prof. Ahmad A.N. Neaz, DSSc., American International University-Bangladesh , Email: aneaz@aiub.edu

Today, when the galaxy of knowledge, be it social, political, economic or scientific is expanding at an unprecedented pace, new questions and new interests require us to enter into a new search for a new answer. For many millennia knowledge was exclusively confined under the grip of subjectivity and pre-conceived ideas. Although, Greek scholars started to think objectively the Newtonian paradigm came as a major breakthrough in this regard. The ultimate outcome turned out to be the development of a 'Positivistic methodology', solely relying on empirical evidence.

Social scientists also pretended to follow scientific method and their search for objectivity was the foundation of research endeavor. They also followed Newtonian philosophy by considering a closed autonomous system, ruled by endogenous factors of highly selective nature, self regulating and moving to a determinate predictable point in terms of linear, stable and equilibrium analysis. Social science, particularly economics ahead of others, claims itself as a 'value free science' in order to follow positivistic methodology, depended solely on empirical evidence. Consequently, it discards ethics, values and any subjective involvement as idealistic rather than realistic. For nearly a century, in order to become increasingly scientific, ethics has been abandoned by many disciplines and ultimately, ethics has been tethered around and nurtured by philosophy only. Einstein tried to synthesize the positivist accommodating the 'world of idea' in the field of research. M.K Gandhi was the first person to challenge economists as a 'value free' subject.

Bioethics could be termed as a landmark in order to rehabilitate ethics. It is for sure that within near future ethics will be the guiding philosophy of all the disciplines of knowledge. In order to achieve that, education and research method need to be redesigned to developed epistemology. It is a fallacy of the positivistic methodology that there will be no subjective involvement. In the field of social sciences where events or phenomena have unique particularity and have no scope for repeated experiment, empirical evidence must be supported by rational thinking. Otherwise it will lead to empiricism which may not be considered as knowledge even. Application of intensive observation, RRA, PRA and other methods have been supplementing and complementing the limitations of positivistic approach. Amartya Sen tried to introduce values in economics but in vain.

Development economics initially considered 'economic growth' or GNI as the yardstick of development. Since mid 1970s it has been shifted to 'human development' which has been intensified under Millennium Development Goals. Economists yet to conceive ethics as a guiding philosophy which may further shift the discipline from human development to 'humane development' emancipating human civilization from the realm of poverty, greed and inhumanity to the arena of welfare, peace and global harmony. 